\title{
DEPENDENCE AND SENSITIVITY ON THE AEROTHERMOCHEMICAL MODEL OF ATMOSPHERIC REENTRY TRAJECTORIES
}

\author{
A. Viviani ${ }^{1}$, L. Savino ${ }^{1}$, and G. Pezzella ${ }^{2}$ \\ ${ }^{1}$ Seconda Università di Napoli (SUN) \\ Dipartimento di Ingegneria Aerospaziale e Meccanica (DIAM) \\ Via Roma 29, Aversa 81031, Italy \\ ${ }^{2}$ Centro Italiano Ricerche Aerospaziali (CIRA) \\ Via Maiorise, Capua 81043, Italy
}

\begin{abstract}
Several numerical analyses have been conducted to examine the effects of some state-of-the-art chemistry models on the aerothermodynamic performances of hypervelocity blunt vehicles. At the beginning, the reentry flight scenario has been defined, and the aeroheating environment has been analyzed, for the achievement of a realistic representation of the flight trajectory for a preliminary estimation of real gas effects. After the definition of the freestream conditions in which the peak heating occurs, several set of reactions have been analyzed in numerical computations. In this way, it has been possible to carry out a dispersion analysis, due to the aerothermochemical model, of the vehicle flight scenario. In detail, it has been analyzed the influence of the technique for the aerodynamic database definition (engineering, panel, and viscous computations methods) on remarkable parameters like peak heating, thermal load, crossrange, and downrange. Then, the analysis of different kind of reactions allows to investigate the reaction mechanism and to understand the main dissociation reactions occurring in high energy flows.
\end{abstract}

\section{INTRODUCTION}

This paper deals with the influence of the accuracy of the aerothermochemical modeling of air on the flight scenario assessment of reentry vehicles. Accurate prediction of hypersonic flowfields requires accurate real gas formulation [1]. As the static temperature behind the bow shock rises, transport quantities change nonlinearly and the factor $E_{a} /(R T)$ (i. e., the Zel'dovich number) begins to approach unity, thus loading to flow molecules dissociation. When this happens, air

This is an Open Access article distributed under the terms of the Creative Commons Attribution-Noncommercial License 3.0, which permits unrestricted use, distribution, and reproduction in any noncommercial medium, provided the original work is properly cited. 
chemistry must be considered [2]. So, a number of questions must be answered as, for example, air modeling effect on atmospheric reentry trajectories. Indeed, it is well known that real gas effects can significantly influence both the aerodynamics and the aerothermodynamics of reentry vehicle $[3,4]$. On the other hand, reentry trajectory calculation dictates the determination of vehicle aerodynamics. Therefore, accurate modeling of flow physics, in particular, flow chemistry, is mandatory within numerical computation of vehicle reentry scenario [5]. This research topic has been stressed in this paper in the framework of a Low Earth Orbit (LEO) reentry of an Apollo-shaped capsule reentry vehicle. In particular, special attention has been focused to the chemical nonequilibrium effects on the atmospheric reentry and a dispersion analysis of the trajectory due to "chemical" effects has been performed. Indeed, a realistic representation of the trajectory is fundamental to accurately predict the reentry loading environment that the vehicle has to withstand during descent.

At the beginning, it is necessary to define both the aerodynamic database (AEDB) and the aerothermodynamic database (ATDB) of the vehicle; to this purpose, different methodologies can be used such as, for example, the Surface Inclination Methods (SIM) [1]. The aerodynamic database permits to obtain a preliminary assessment of the reentry trajectory and, hence, of its aerothermal environment, once the preliminary reentry flight scenario is provided. Then, computational fluid dynamics (CFD) analyses were carried out, in the light of space-based and trajectory-based design approaches, to recalculate the AEDB and to refine the reentry trajectory.

The best accuracy can be obtained through the CFD analysis; so, we could think to skip the phase of the solution of the reentry problem through preliminary models and going directly to the CFD analysis [6, 7]. However, high accuracy in modeling flow and chemistry coupling may result only in a poor increase of accuracy of CFD results, despite the high modeling efforts and the increased computational cost. So, one must balance the theoretical and CPU time effort needed to use a more general and sophisticated model against the expected accuracy of the numerical results. To answer this question, a step by step increased-complexity investigation has been carried out, to highlight the influence of flow chemistry effects on capsule aerodynamic performance. To this end, a number of key reentry parameters have been collected, such as the vehicle peak heating, thermal load, crossrange, and downrange, depending on the method of analysis used such as Newtonian, modified Newtonian, Panel, CFD with perfect gas, CFD with reacting mixture, to have an idea of the incidence of the approximation used in the calculation.

In conclusion, the work confirms that high temperature transport phenomena markedly influence the flowfield around the vehicle and, in turn, capsule aerodynamics, but it also stresses that with an acceptable loss of results accuracy, it is not needed to use the models of so high complexity, thus saving much computing time. 


\section{PRELIMINARY CAPSULE REENTRY SCENARIO}

During the reentry, the capsule falls in the Earth's atmosphere travelling at hypersonic speed for most of the reentry time. In these conditions, the aerodynamic forces are mainly effected by the pressure and can be easily estimated with approximated methods, like those of the Impact Newtonian Theory [2].

In the next section, the results obtained through the analytical formulas of the Newtonian theory will be compared with those computed with panel method, by means of the SIM code developed at CIRA. The pressure acting on each panel is valued through several compression/expansion methods such as tangent cone, Newtonian, and modified Newtonian. Starting from the preliminary assessment of capsule aerodynamics, the reentry scenario shown in Fig. 1 is provided for the capsule vehicle shown in Fig. 2, where main geometric features are given [6].

The heat flux distribution at capsule stagnation point vs. velocity is reported in Fig. $3 a$, for cold wall boundary condition and different engineering relationships [2, 8-12]. The heat load corresponding to the heat fluxes of Fig. $3 a$ is

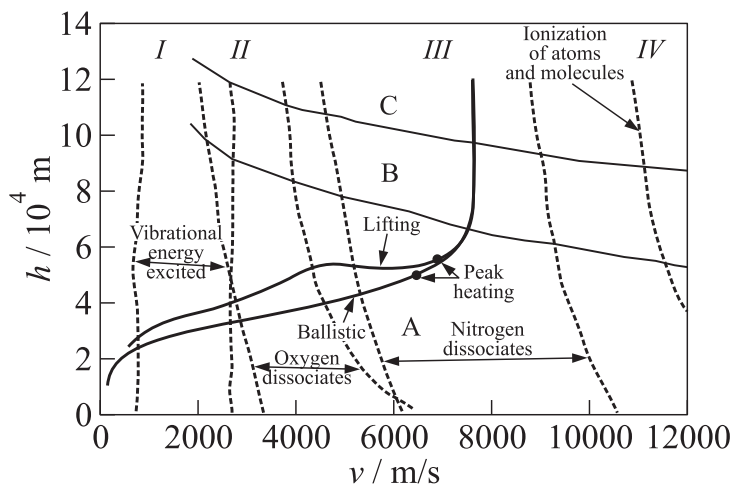

Region with chemical and thermal nonequilibrium Region Aerothermal phase

A Chemical and thermal equilibrium

B Chemical nonequilibrium with thermal equilibrium

C Chemical and thermal nonequilibrium

Chemical species in high-temperature air

\begin{tabular}{crl}
\hline Region & Model & \multicolumn{1}{c}{ Species } \\
\hline I & 2 species & $\mathrm{O}_{2}, \mathrm{~N}_{2}$ \\
II & 5 species & $\mathrm{O}_{2}, \mathrm{~N}_{2}, \mathrm{O}, \mathrm{N}, \mathrm{NO}$ \\
III & 7 species & $\mathrm{O}_{2}, \mathrm{~N}_{2}, \mathrm{O}, \mathrm{N}, \mathrm{NO}, \mathrm{NO}^{+}, e^{-}$ \\
IV & 11 species & $\mathrm{O}_{2}, \mathrm{~N}_{2}, \mathrm{O}, \mathrm{N}, \mathrm{NO}, \mathrm{NO}^{+}, \mathrm{O}_{2}^{+}, \mathrm{N}_{2}^{+}, \mathrm{O}^{+}, \mathrm{N}^{+}, e^{-}$ \\
\hline
\end{tabular}

Figure 1 Reentry flight scenario for the capsule vehicle of Fig. 2 


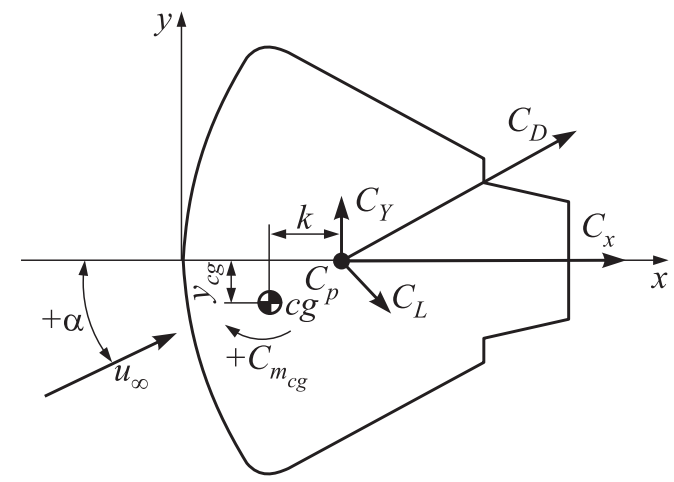

Figure 2 Capsule OML (outer mold line) used for Newtonian method (diameter $=5 \mathrm{~m}$; nose radius $=6.05 \mathrm{~m}$; sidewall angle $\theta=33^{\circ}$; overall height $=3.8 \mathrm{~m}$ )

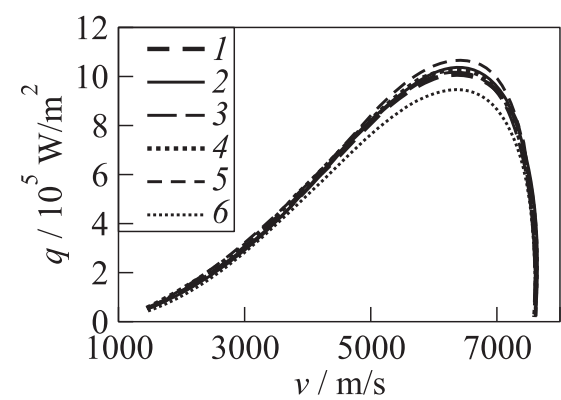

(a)

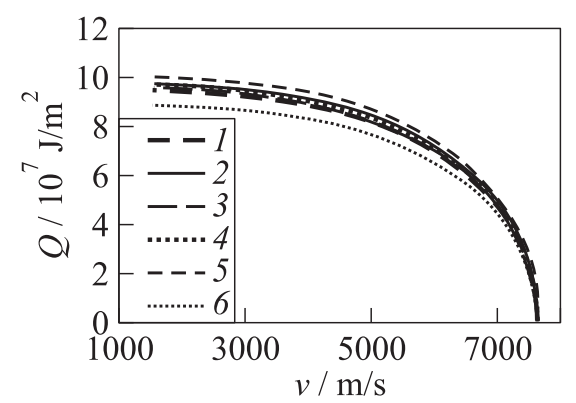

(b)

Figure 3 Stagnation point heat flux $(a)$ and heat load $(b)$ vs. velocity for approximate formulas: $1-[2] ; 2-[8] ; 3-[9] ; 4-[10] ; 5-[11]$; and $6-[12]$

shown in Fig. $3 b$. Only cold wall condition is reported because it is conservative with respect to radiative equilibrium wall condition as shown by the authors' computation, for both conditions, of heat flux vs. altitude.

\section{REENTRY TRAJECTORY DISPERSION}

The uncertainties that affect the aerodynamic performances of the reentry vehicle result in the trajectory dispersion, as reported in Fig. 4 [5]. For example, for both ballistic and lifting reentry, it is shown that the trajectory dispersion due to an increasing and/or reducing of lift and drag coefficients are of $10 \%, 20 \%$, and $30 \%$. 


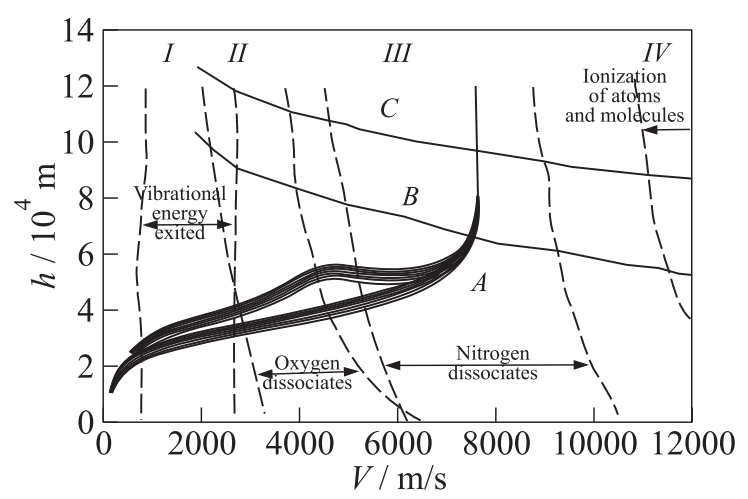

(a)

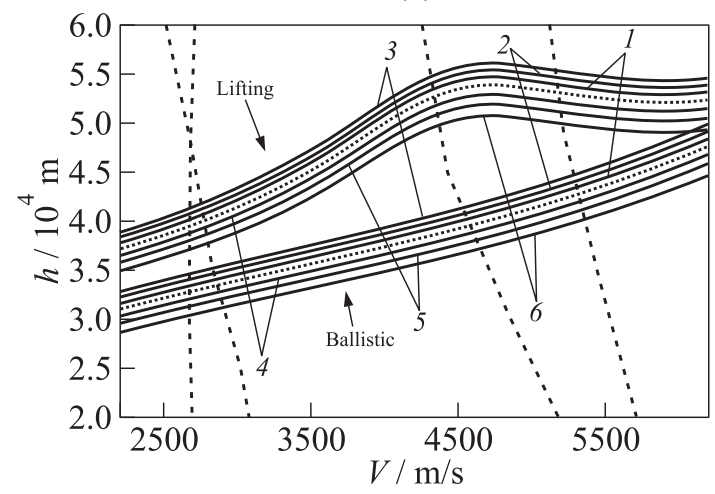

(b)

Figure 4 Reentry corridor: $1-+10 \% ; 2-+20 \% ; 3-+30 \% ; 4--10 \% ; 5-$ $-20 \%$; and $6--30 \%$

To appreciate the effect of trajectory dispersion, a set of significant parameters, such as heat flux, heat load, crossrange, and downrange, has been considered. Tables 1 to 3 give, for these parameters, the percentage variations, with

Table 1 Ballistic trajectory

\begin{tabular}{lcccccc}
\hline \multirow{2}{*}{ Parameters } & \multicolumn{7}{c}{$\Delta C_{D}$} \\
\cline { 2 - 7 } & $+10 \%$ & $-10 \%$ & $+20 \%$ & $-20 \%$ & $+30 \%$ & $-30 \%$ \\
\hline Crossrange & - & - & - & - & - & - \\
Downrange & -0.7 & 0.8 & -1.4 & 1.7 & -2 & 2.7 \\
Thermal load & -4.6 & 5.3 & -8.6 & 11.5 & -12.2 & 18.9 \\
Peak heating & -4.9 & 5.2 & -9.4 & 10.7 & -13.7 & 16.7 \\
\hline
\end{tabular}


Table 2 Lifting trajectory

\begin{tabular}{lcccccc}
\hline \multirow{2}{*}{ Parameters } & \multicolumn{7}{c}{$\Delta C_{D, L}$} \\
\cline { 2 - 7 } & $+10 \%$ & $-10 \%$ & $+20 \%$ & $-20 \%$ & $+30 \%$ & $-30 \%$ \\
\hline Crossrange & 0 & 0 & 0 & 0 & 0 & 0 \\
Downrange & -0.5 & 0.6 & -1.0 & 1.2 & -1.4 & 1.9 \\
Thermal load & -4.8 & 5.5 & -8.9 & 12 & -12.6 & 19.9 \\
Peak heating & -4.7 & 5.1 & -8.9 & 10.7 & -12.8 & 17 \\
\hline
\end{tabular}

Table 3 Lifting trajectory with constant $C_{L}$

\begin{tabular}{lrrrrrr}
\hline \multirow{2}{*}{ Parameters } & \multicolumn{7}{c}{$\Delta C_{D}$} \\
\cline { 2 - 7 } & $+10 \%$ & $-10 \%$ & $+20 \%$ & $-20 \%$ & $+30 \%$ & $-30 \%$ \\
\hline Crossrange & -17.3 & 23.5 & -30.6 & 56.2 & -40.8 & 104.1 \\
Downrange & -4.7 & 5.4 & -8.6 & 11.3 & -11.8 & 17.4 \\
Thermal load & -8.1 & 10 & -14.7 & 21.9 & -20.3 & 35.1 \\
Peak heating & -3.0 & 3.1 & -5.8 & 6.2 & -8.6 & 9.6 \\
\hline
\end{tabular}

respect to the nominal value, in correspondence to the percentage variations of the aerodynamic coefficients. They refer to the three cases analyzed: ballistic entry (see Table 1), lifting entry varying $C_{L}$ and $C_{D}$ (see Table 2), and lifting entry keeping constant $C_{L}$ (see Table 3 ).

\section{COMPUTATIONAL ANALYSIS}

Several computational analyses of the flowfield are performed to assess the effects of flow chemistry on the capsule aerodynamics accuracy, by using viscous computations for perfect gas and for gas mixture with chemical nonequilibrium, in the case of continuum laminar regime hypothesis. The complete physical and mathematical model is detailed elsewhere [13-15].

\section{REACTION MECHANISMS}

The accuracy of capsule AEDB markedly depends on the reaction mechanisms and chemical kinetics considered in the numerical computation. Considering that reentering from LEO, no flowfield ionization takes place, the gas can be approximated as a finite rate mixture of $\mathrm{O}_{2}, \mathrm{~N}_{2}, \mathrm{NO}, \mathrm{O}$, and $\mathrm{N}$ species. In fact, in the hypersonic reentry flow, the region under consideration, the gas temperature ranges between $2000-6000 \mathrm{~K}$ where negligible ionization occurs [2]. 
Three dissociation reactions and two exchange reactions are generally considered as reaction mechanisms:

$$
\begin{aligned}
\mathrm{N}_{2}+M & \rightarrow 2 \mathrm{~N}+M ; \\
\mathrm{O}_{2}+M & \rightarrow 2 \mathrm{O}+M ; \\
\mathrm{NO}+M & \rightarrow \mathrm{N}+\mathrm{O}+M ; \\
\mathrm{NO}+\mathrm{O} & \rightarrow \mathrm{N}+\mathrm{O}_{2} ; \\
\mathrm{N}_{2}+\mathrm{O} & \rightarrow \mathrm{NO}+\mathrm{N}
\end{aligned}
$$

where $M=\mathrm{N}_{2}, \mathrm{O}_{2}, \mathrm{NO}, \mathrm{N}$, and $\mathrm{O}$ for a total number of 17 reactions [6].

Note that NO plays an important kinetic role, although it may be present only in relatively small amounts, through the fast bimolecular exchange. In the next section, models with a number of $4,8,10,12$, and 15 reactions will also be analyzed. These models were obtained from the most complex model (set of 17 reactions) reported above, neglecting from time to time several reactions; see $[13,15]$ for more details.

The 4-reaction model can be presented schematically in the following way:

$$
\begin{aligned}
\mathrm{N}_{2}+M & \rightarrow 2 \mathrm{~N}+M ; \\
\mathrm{O}_{2}+M & \rightarrow 2 \mathrm{O}+M ; \\
M & =\mathrm{N}_{2}, \mathrm{O}_{2} .
\end{aligned}
$$

The 8-reaction system can be expressed in this way:

$$
\begin{aligned}
\mathrm{N}_{2}+M & \rightarrow 2 \mathrm{~N}+M ; \\
\mathrm{O}_{2}+M & \rightarrow 2 \mathrm{O}+M ; \\
M & =\mathrm{N}_{2}, \mathrm{O}_{2}, \mathrm{~N}, \mathrm{O} .
\end{aligned}
$$

For the 10-reaction model,

$$
\begin{aligned}
\mathrm{N}_{2}+M & \rightarrow 2 \mathrm{~N}+M \\
\mathrm{O}_{2}+M & \rightarrow 2 \mathrm{O}+M \\
\mathrm{NO}+\mathrm{O} & \rightarrow \mathrm{N}+\mathrm{O}_{2} ; \\
\mathrm{N}_{2}+\mathrm{O} & \rightarrow \mathrm{NO}+\mathrm{N} ; \\
M & =\mathrm{N}_{2}, \mathrm{O}_{2}, \mathrm{~N}, \mathrm{O} .
\end{aligned}
$$

The 12-reaction system can be presented schematically in the following way:

$$
\begin{aligned}
\mathrm{N}_{2}+M & \rightarrow 2 \mathrm{~N}+M \\
\mathrm{O}_{2}+M & \rightarrow 2 \mathrm{O}+M \\
\mathrm{NO}+\mathrm{O} & \rightarrow \mathrm{N}+\mathrm{O}_{2} ; \\
\mathrm{N}_{2}+\mathrm{O} & \rightarrow \mathrm{NO}+\mathrm{N} ; \\
M & =\mathrm{N}_{2}, \mathrm{O}_{2}, \mathrm{NO}, \mathrm{N}, \mathrm{O} .
\end{aligned}
$$


The 15-reaction model includes the following reactions:

$$
\begin{aligned}
\mathrm{N}_{2}+M & \rightarrow 2 \mathrm{~N}+M ; \\
\mathrm{O}_{2}+M & \rightarrow 2 \mathrm{O}+M ; \\
\mathrm{NO}+M & \rightarrow 2 \mathrm{O}+M ; \\
M & =\mathrm{N}_{2}, \mathrm{O}_{2}, \mathrm{NO}, \mathrm{N}, \mathrm{O} .
\end{aligned}
$$

\section{NUMERICAL RESULTS}

Computations are carried out at the following freestream conditions both for air considered as perfect gas and as reacting mixture: $H=50 \mathrm{~km} ; P_{\text {inf }}=79.78 \mathrm{~Pa}$; $T_{\mathrm{inf}}=270.65 \mathrm{~K} ; M_{\mathrm{inf}}=20 ;\left[\mathrm{N}_{2}\right]=0.79 ;[\mathrm{N}]=0 ;\left[\mathrm{O}_{2}\right]=0.21 ;[\mathrm{O}]=0 ;$ and $[\mathrm{NO}]=0$.

Perfect gas simulations compared to reacting mixture simulations allowed to evaluate the entity of real gas effects on capsule aerodynamics and aerothermodynamics. The flowfield past the vehicle is shown in Fig. 5, where the differences in static temperature distribution and standoff distance are evident between results for perfect gas and real gas computations (17 reactions).

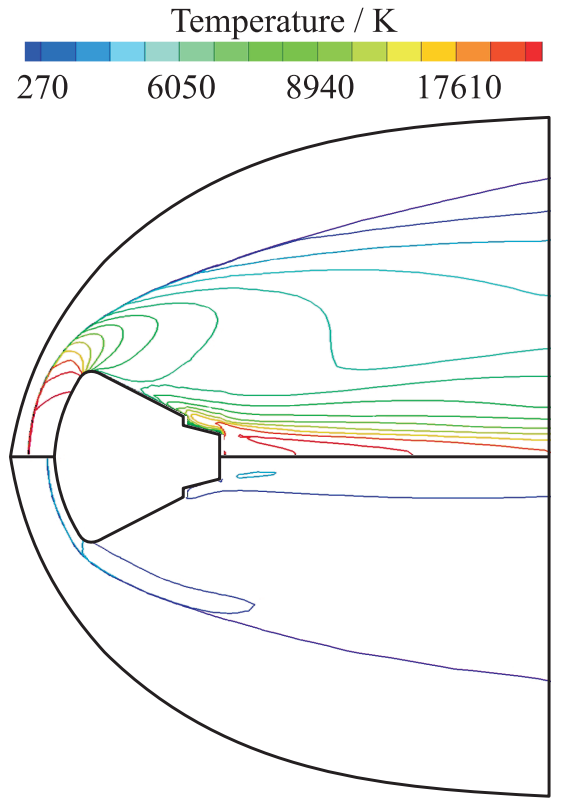

Figure 5 Temperature contours for perfect gas (up) and real gas (down). (Refer Viviani et al., p.260.)
Temperature / K

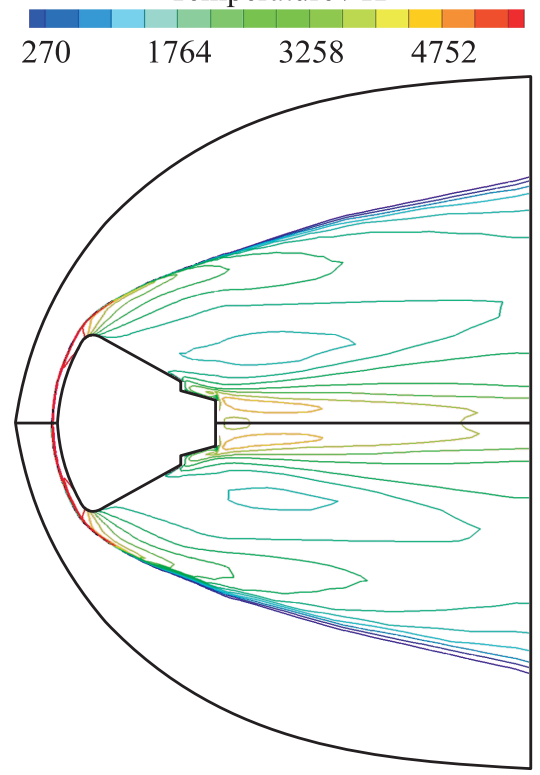

Figure 6 Temperature contours comparison between 17- (up) and 10-reaction (down) systems. (Refer Viviani et al., p.260.) 
A comparison between temperature contours for the 17- and the 10-reaction cases is shown in Fig. 6. It can be observed that temperature contours and standoff distances are very similar.

The 12-reaction model differs from that constituted by 10-reaction system because it counts $\mathrm{NO}$ as a collision partner in $\mathrm{N}_{2}$ and $\mathrm{O}_{2}$ dissociation reactions. Also, in this case, the collision reactions of $\mathrm{NO}$ are neglected. Figure 7 shows the comparison of the temperature contours between the 12- and 17reaction systems.

In Fig. 8, the diagrams of temperature distribution along stagnation line and convective heat flux distribution over the capsule fore-body centerline are shown for the different reaction mechanisms herein analyzed: 4-, 8-, 10-, 12-, 15-, and 17-reaction systems

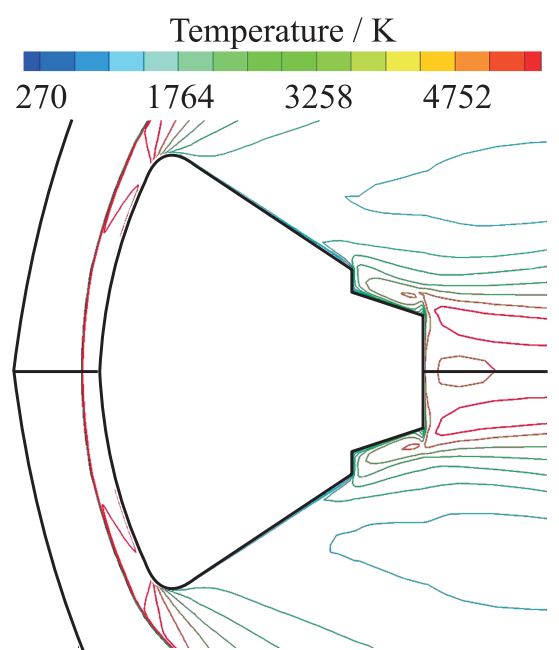

Figure 7 Temperature contours for 17- (up) and 12-reaction (down) systems. (Refer Viviani et al., p. 261.) plus the Zel'dovich system [13].

Figure $8 a$ shows how the 4-reaction and Zel'dovich systems are characterized by nonequilibrium, 15-reaction system presents instead a trend similar to the 8-reaction system, the 10- and 12-reaction systems show, finally, a trend of the temperature very similar to the 17-reaction system, confirming the analogy detected through the analysis done for the temperature contours. Curves tend to

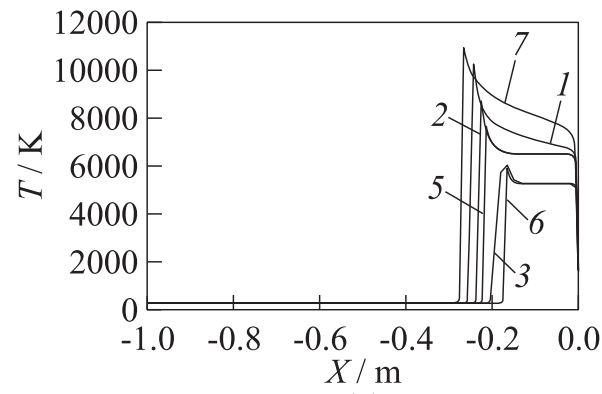

(a)

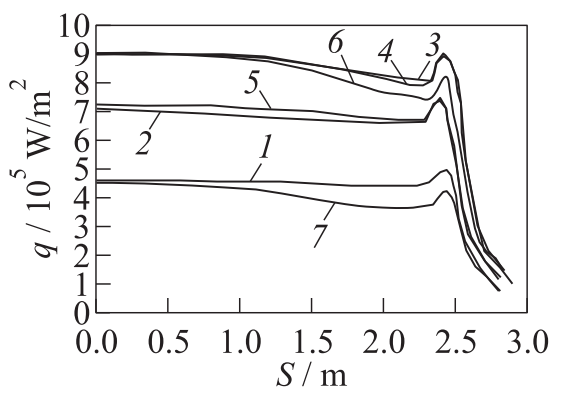

(b)

Figure 8 Comparison of temperature distribution along the stagnation line $(a)$ and of convective heat flux along the nose surface $(b)$ : $1-4$ reactions; $2-8 ; 3-10$; $4-12 ; 5-15 ; 6-17$ reactions; and $7-$ Zel'dovich system 
overlap for the 12- and 17-reaction systems. Figure $8 b$ shows how the analogies detected in the temperature distribution along the stagnation line continue to be valid for the heat flux surface distribution. So, it can be concluded that the 10 - and 12-reaction systems are adequate also under the aerodynamic heating aspect.

\section{ANALYSIS OF THE CAPSULE REENTRY TRAJECTORY DISPERSION}

In Fig. 9, the values of $C_{D}$ and $C_{M}$ (relative to the center of gravity, C.G.) for the different methodologies (Newtonian $(\mathrm{N})$, modified Newtonian $(\mathrm{MN})$, panel methods, CFD) and for the different reaction mechanisms are reported.

As one can see in Fig. 9, the MN offers in a preliminary phase a valid technique for the aerodynamic coefficients determination. Less accurate are results obtained with PG (CFD with perfect gas) and with the VECC (viscous effects on complex configurations) panel method code.

Now, the percentage error of $C_{D}$ can be determined, with reference to the value of the 17-reaction system through the CFD analysis, for each methodology analyzed, as reported on Tables 4 and 5 . In these tables, Table 1 is duplicated and grey color marked columns indicate where the errors for the different methods take place.

Now, one can observe that the reentry corridor, determined at the beginning without the knowledge of the size order of mistakes depending on methodology and set of reactions used, was too wide. The areas were defined by considering errors with a minimum variation in Tables $1-3$ of $10 \%$, while the maximum error is about $8 \%$. So, it is necessary to redefine the design limits: in Tables 6-8, a step of $2.5 \%$ was considered for the aerodynamics coefficients variation.

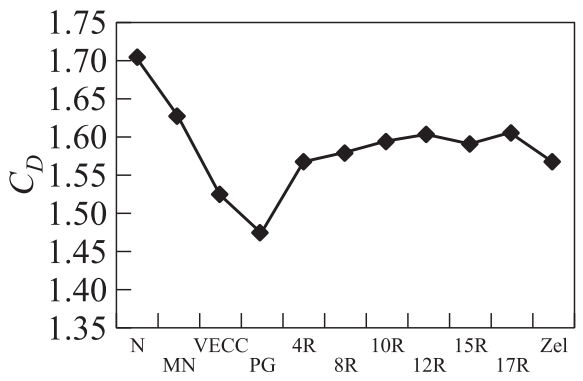

(a)

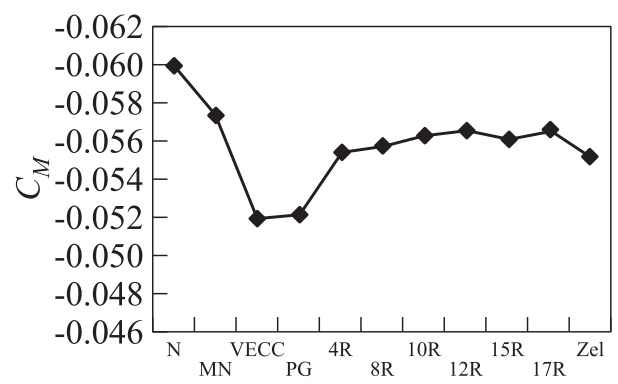

(b)

Figure $9 C_{D}(a)$ and $C_{M}(b)$ for the different methods analyzed in the present paper 
Table 4 Errors of $C_{D}$ for different methodologies and errors of the main parameters

\begin{tabular}{|c|c|c|c|c|c|c|}
\hline & \multirow{2}{*}{\multicolumn{2}{|c|}{ Method }} & \multirow{2}{*}{\multicolumn{2}{|c|}{ Errors of $C_{D}$}} & & \\
\hline & & & & & & \\
\hline & \multicolumn{2}{|c|}{$\mathrm{MN}(\gamma=1.2)$} & \multicolumn{2}{|c|}{1.606} & & \\
\hline & \multicolumn{2}{|c|}{$\mathrm{MN}(\gamma=1.4)$} & \multicolumn{2}{|c|}{-2.426} & & \\
\hline & \multicolumn{2}{|l|}{$\mathrm{N}$} & \multicolumn{2}{|c|}{6.445} & & \\
\hline & \multicolumn{2}{|c|}{ VECC } & \multicolumn{2}{|c|}{-4.635} & & \\
\hline \multirow{2}{*}{ Parameters } & \multicolumn{6}{|c|}{$\Delta C_{D}$} \\
\hline & $+10 \%$ & $-10 \%$ & $+20 \%$ & $-20 \%$ & $+30 \%$ & $-30 \%$ \\
\hline Crossrange & - & - & - & $\overline{-}$ & - & - \\
\hline Downrange & -0.7 & 0.8 & -1.4 & 1.7 & -2 & 2.7 \\
\hline Thermal load & -4.6 & 5.3 & -8.6 & 11.5 & -12.2 & 18.9 \\
\hline Peak heating & -4.9 & 5.2 & -9.4 & 10.7 & -13.7 & 16.7 \\
\hline
\end{tabular}

Table 5 Errors of $C_{D}$ for different reactions and CFD results, and errors of the main parameters

\begin{tabular}{|c|c|c|c|c|c|c|c|}
\hline & \multirow{2}{*}{\multicolumn{2}{|c|}{ System }} & & & & \\
\hline & & & $C_{D}$ & & & & \\
\hline & \multicolumn{2}{|c|}{ Ideal gas } & \multicolumn{2}{|c|}{1.475} & -7.812 & & \\
\hline & \multicolumn{2}{|c|}{ 4-reaction } & \multicolumn{2}{|c|}{1.565} & -2.219 & & \\
\hline & \multicolumn{2}{|c|}{ 8-reaction } & \multicolumn{2}{|c|}{1.573} & -1.696 & & \\
\hline & \multicolumn{2}{|c|}{ 10-reaction } & \multicolumn{2}{|c|}{1.589} & -0.714 & & \\
\hline & \multicolumn{2}{|c|}{ 12-reaction } & \multicolumn{2}{|c|}{1.599} & -0.058 & & \\
\hline & \multicolumn{2}{|c|}{ 15-reaction } & \multicolumn{2}{|c|}{1.584} & -0.992 & & \\
\hline & \multicolumn{2}{|c|}{ 17-reaction } & \multicolumn{2}{|c|}{1.600} & - & & \\
\hline & \multicolumn{2}{|c|}{ Zel'dovich } & \multicolumn{2}{|c|}{1.559} & -2.587 & & \\
\hline \multirow{2}{*}{ Parameters } & \multicolumn{7}{|c|}{$\Delta C_{D}$} \\
\hline & $+10 \%$ & $-10^{\circ}$ & & $+20 \%$ & $-20 \%$ & $+30 \%$ & $-30 \%$ \\
\hline Crossrange & - & - & & - & - & - & - \\
\hline Downrange & -0.7 & 0.8 & & -1.4 & 1.7 & -2 & 2.7 \\
\hline Thermal load & -4.6 & 5.3 & & -8.6 & 11.5 & -12.2 & 18.9 \\
\hline Peak heating & -4.9 & 5.2 & & -9.4 & 10.7 & -13.7 & 16.7 \\
\hline
\end{tabular}

Table 6 Ballistic trajectory

\begin{tabular}{lcccccc}
\hline \multirow{2}{*}{ Parameters } & \multicolumn{7}{c}{$\Delta C_{D}$} \\
\cline { 2 - 7 } & $+2.5 \%$ & $-2.5 \%$ & $+5 \%$ & $-5 \%$ & $+7.5 \%$ & $-7.5 \%$ \\
\hline Crossrange & - & - & - & - & - & - \\
Downrange & -0.2 & 0.2 & -0.4 & 0.4 & -0.6 & 0.6 \\
Thermal load & -1.2 & 1.3 & -2.4 & 2.6 & -3.4 & 3.7 \\
Peak heating & -1.3 & 1.3 & -2.5 & 2.7 & -3.5 & 3.9 \\
\hline
\end{tabular}


Table 7 Lifting trajectory

\begin{tabular}{lcccccc}
\hline \multirow{2}{*}{ Parameters } & \multicolumn{7}{c}{$\Delta C_{D, L}$} \\
\cline { 2 - 7 } & $+2.5 \%$ & $-2.5 \%$ & $+5 \%$ & $-5 \%$ & $+7.5 \%$ & $-7.5 \%$ \\
\hline Crossrange & 0 & 0 & 0 & 0 & 0 & 0 \\
Downrange & -0.1 & 0.1 & -0.3 & 0.3 & -0.4 & 0.4 \\
Thermal load & -1.3 & 1.3 & -2.5 & 2.7 & -3.4 & 3.8 \\
Peak heating & -1.2 & 1.2 & -2.3 & 2.5 & -3.2 & 3.6 \\
\hline
\end{tabular}

Table 8 Lifting trajectory with constant $C_{L}$

\begin{tabular}{lcccccc}
\hline \multirow{2}{*}{ Parameters } & \multicolumn{7}{c}{$\Delta C_{D}$} \\
\cline { 2 - 7 } & $+2.5 \%$ & $-2.5 \%$ & $+5 \%$ & $-5 \%$ & $+7.5 \%$ & $-7.5 \%$ \\
\hline Crossrange & -4.8 & 5.2 & -9.3 & 10.8 & -12.6 & 15.6 \\
Downrange & -1.4 & 1.5 & -2.7 & 3.1 & -3.7 & 4.4 \\
Thermal load & -2.2 & 2.3 & -4.3 & 4.8 & -5.9 & 6.9 \\
Peak heating & -0.8 & 0.9 & -1.7 & 1.7 & -2.3 & 2.5 \\
\hline
\end{tabular}

Now, the analysis of dispersion of the reentry trajectory, for the various methods and set of reactions, can be performed using the limits defined in Tables 6-8. The results are given in Tables 9 and 10 .

\section{CONCLUDING REMARKS}

The influence of the thermochemical model on the reentry trajectory of capsule vehicle has been discussed. From the results of the research activities, one can deduce that the percentage mistake (evalued relative to the results obtained with 17-reaction set used in the CFD simulations performed) committed in the determination of the AEDB with relation to the method used, falls in a range of about $10 \%$. It has been also considered that an error in the range of $10 \%$ has an important impact on the crossrange and downrange as we can deduce from Tables 1 to 3 . In these tables, one can observe how an alteration of $10 \%$ on $C_{D}$ relative to the nominal conditions gives a variation of $20 \%$ on the crossrange and $5 \%$ on the downrange that means a mistake of about $40 \mathrm{~km}$ on the crossrange and about $150 \mathrm{~km}$ on the downrange, while the authors obtain a mistake of about $10 \mathrm{~km}$ on the crossrange and about $60 \mathrm{~km}$ on the downrange for a variation of $2.5 \%$ on $C_{D}$.

The analysis performed comparing solutions obtained with different sets of reactions highlights how the simplest systems of reactions (4 and 8 reactions) are inadequate under the aeroheating aspect, having observed in these cases the thermal flux in the stagnation point of about $4 \cdot 10^{5} \mathrm{~W} / \mathrm{m}^{2}$ for the 4-reaction system while a value of about $9 \cdot 10^{5} \mathrm{~W} / \mathrm{m}^{2}$ has been determined for the set of 17 reactions. The results associated to the 4 - and 8-reaction systems, however, 
Table 9 Errors of $C_{D}$ for different methodologies and errors of the main parameters

\begin{tabular}{|c|c|c|c|c|c|c|}
\hline & \multirow{2}{*}{\multicolumn{2}{|c|}{ Method }} & & & & \\
\hline & & & \multicolumn{2}{|c|}{ Errors of $C_{D}$} & & \\
\hline & \multicolumn{2}{|c|}{$\mathrm{MN}(\gamma=1.2)$} & \multicolumn{2}{|c|}{1.606} & & \\
\hline & \multicolumn{2}{|c|}{$\mathrm{MN}(\gamma=1.3)$} & \multicolumn{2}{|c|}{-0.497} & & \\
\hline & \multicolumn{2}{|c|}{$\mathrm{MN}(\gamma=1.4)$} & \multicolumn{2}{|c|}{-2.426} & & \\
\hline & \multicolumn{2}{|c|}{$\mathrm{N}$} & \multicolumn{2}{|c|}{6.445} & & \\
\hline & \multicolumn{2}{|c|}{ VECC } & \multicolumn{2}{|c|}{-4.635} & & \\
\hline \multirow{2}{*}{ Parameters } & \multicolumn{6}{|c|}{$\Delta C_{D}$} \\
\hline & $+2.5 \%$ & $-2.5 \%$ & $+5 \%$ & $-5 \%$ & $+7.5 \%$ & $-7.5 \%$ \\
\hline Crossrange & - & - & - & - & - & - \\
\hline Downrange & -0.2 & 0.2 & -0.4 & 0.4 & -0.6 & 0.6 \\
\hline Thermal load & -1.2 & 1.3 & -2.4 & 2.6 & -3.4 & 3.7 \\
\hline Peak heating & -1.3 & 1.3 & -2.5 & 2.7 & -3.5 & 3.9 \\
\hline
\end{tabular}

Table 10 Errors of $C_{D}$ for different reactions and CFD results, and errors on the main parameters

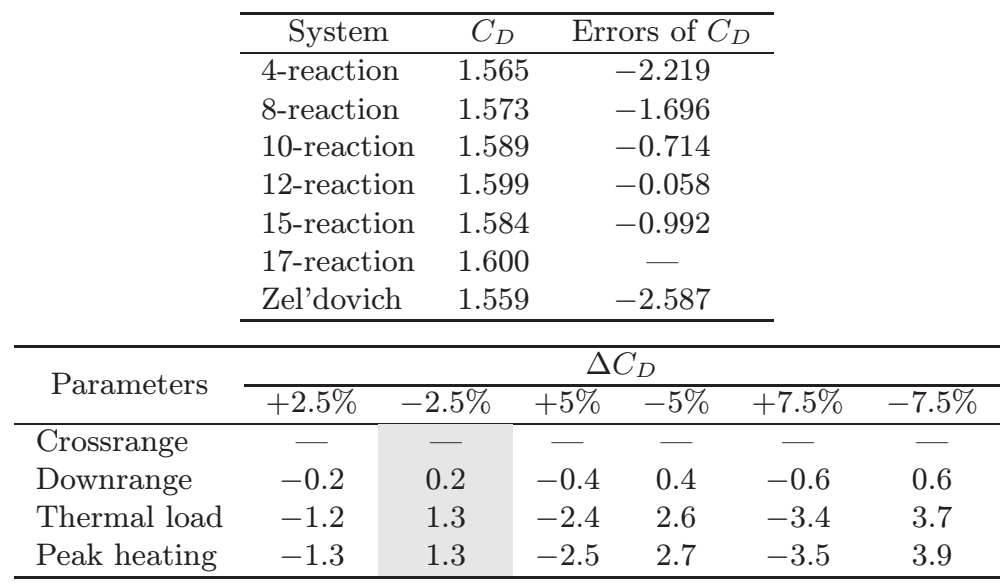

can be considered acceptable from an aerodynamic point of view (error on $C_{D}$ of about $-3 \%$ for the set of 4 -reaction system and $-2 \%$ for the 8 -reaction system), 10 - and 12-reaction systems give minimum gap relative to the 17-reaction one for the both aspects (aerodynamic coefficients and aeroheating).

This kind of analysis highlights the importance of the exchange reactions for the synthesis of NO and that they are predominant relative to the collision reactions of $\mathrm{NO}$, having observed for the set of 15 reactions that accounts this kind of reactions, a departure under the thermodynamic and aerodynamic aspect 
from the set of 17 reactions and an incoming to the 8-reaction system. The Zel'dovich model underlines that the collision reactions of the molecular species and the exchange reactions are not independent from each other but they are strongly connected, having seen a remarkable difference under the aeroheating aspect between this system and the set of 17 reactions.

\section{REFERENCES}

1. Bertin, J. 1994. Hypersonic aerothermodynamics. AIAA education ser. Washington, D.C.: AIAA Inc.

2. Anderson, J. D. 2006. Hypersonic and high temperature gas dynamics. AIAA education ser. 2nd ed. Reston, VA: AIAA Inc. 813 p.

3. Park, C. 1997. Evaluation of real-gas phenomena in high enthalpy impulse test facilities: A review. J. Thermophysics Heat Transfer 11(1):330-38.

4. Livier, P. A., S. D. Habchi, S. I. Burnell, and J.S. Lingard. 2003. Computational fluid dynamics prediction of the beagle 2 aerodynamic database. J. Spacecraft Rockets 40(5):632-38.

5. Queen, E. M., F. M. Cheatwood, R. W. Powell, R. D. Braun, and C. T. Edquist. 1999. Mars Polar Lander aerothermodynamic and entry dispersion analysis. J. Spacecraft Rockets 36(3):421-28.

6. Gupta, R. N., J. M. Yos, R. A. Thompson, and K. P. Lee. 1990. A review of reaction rates and thermodynamic and transport properties for an 11-species air model for chemical and thermal nonequilibrium calculations to 30,0000 K. NASA/RP-1232.

7. Murphy, K. J., R. J. Nowak, R. A. Thompson, B. R. Hollis, and R. Prabhu. 2001. X33 hypersonic aerodynamic characteristics. J. Spacecraft Rockets 38(5):670-83.

8. Detra, R.W., N.H. Kemp, and F. R. Riddell. 1957. Addendum to heat transfer to satellite vehicles reentering the atmosphere. Jet Propuls. 27(12):1256-57.

9. Fay, J., and F. Riddell. 1958. Theory of stagnation point heat transfer in dissociated air. J. Aeronautical Sci. 25(2):72-85.

10. Sutton, K., and R. Graves, Jr. 1971. A general stagnation-point convective-heating equation for arbitrary gas mixtures. NASATR R-376.

11. Zoby, E. V., J. N. Moss, and K. Sutton. Approximate convective-heating equations for hypersonic flows. J. Spacecreft Rockets 18(1):64-70.

12. Scott, C. D., R. C. Ried, R. J. Maraia, C.P. Li, and S. M. Derry. 1985. An AOTV aeroheating and thermal protection study. In: Thermal design of aeroassisted orbital transfer vehicles. Ed. H. F. Nelson. Progress in astronautics and aeronautics ser. N.Y.: AIAA Inc. 96:198-229.

13. Viviani, A., G. Pezzella, and S. Borrelli. 2008. Effect of finite rate chemical models on the aerothermodynamics of reentry capsules. AIAA Paper No. 2006-2668.

14. Viviani, A., G. Pezzella, and D. Cinquegrana. 2006. Aerothermodynamic analysis of an Apollo-like reentry vehicle. AIAA Paper No. 2006-8082.

15. Viviani, A., and G. Pezzella. 2007. Influence of surface catalyticity on reentry aerothermodynamics and heat shield. AIAA Paper No. 2007-4047. 